Brazilian Journal

of Chemical

ISSN 0104-6632

Printed in Brazil

Engineering

Vol. 35, No. 02, pp. 429 - 440, April - June, 2018

(cc) BY

dx.doi.org/10.1590/0104-6632.20180352s20160415

\title{
UTILIZATION OF AGROINDUSTRIAL BY-PRODUCTS AS SUBSTRATE IN ENDOGLUCANASE PRODUCTION BY Streptomyces diastaticus PA-01 UNDER SUBMERGED FERMENTATION
}

\author{
A.S.R. Bispo ${ }^{1}$, J.P. Andrade ${ }^{1}$, D.T. Souza ${ }^{1}$, Z.N.S. Teles ${ }^{1}$ and R.P. \\ Nascimento $^{2 *}$ \\ ${ }^{1}$ Centro de Ciências Agrárias, Ambientais e Biológicas, Universidade Federal do \\ Recôncavo da Bahia (UFRB), Zip Code: 44380-000, Cruz das Almas, BA, Brazil. \\ ${ }^{2}$ Dep. Engenharia Bioquímica, Escola de Química, CT, Universidade Federal do Rio \\ de Janeiro (UFRJ), Zip Code: 21941-909, Rio de Janeiro, RJ, Brazil.
}

(Submitted: July 4, 2016; Revised: November 25, 2016; Accepted: January 2, 2017)

\begin{abstract}
Endoglucanase production under submerged fermentation was studied using sugarcane bagasse (SCB) and oat bran (OB) as carbon source and corn steep liquor (CSL) as nitrogen source, in different concentrations using factorial design. Streptomyces diastaticus PA-01, isolated from a soil cave in Brazil, was selected as cellulolytic strain. The results after experimental validation showed that a medium containing $2.4 \%(w / v) \mathrm{SCB}$ and $1.3 \%(w / v)$ CSL led to the highest production, $1,180.3$ U.L $\mathrm{L}^{-1}$ of endoglucanase, after the $5^{\text {th }}$-day. A good level of endoglucanase $\left(1,039.3 \mathrm{U}^{-L^{-1}}\right)$ was obtained after the $4^{\text {th }}$-day when $2.0 \%(w / v)$ OB and $1.65 \%(w / v)$ CSL were used. The $\mathrm{pH}$ and temperature profiles showed thermoacidophilic endoglucanase activity, with $70 \%$ of maximum activity at $50^{\circ} \mathrm{C}$, after 4 hours of pre-incubation. This is the first report on endoglucanase production by $S$. diastaticus PA-01 in the presence of SCB and OB. The strong positive effects of some metal ions $\left(\mathrm{Zn}^{2+}\right.$, $\mathrm{Mn}^{2+}$ and $\mathrm{Ba}^{2+}$ ) on endoglucanase activity when this strain was grown on $\mathrm{OB}$ is an interesting biochemical characteristic for future biotechnological applications.
\end{abstract}

Keywords: Streptomyces diastaticus PA-01, endoglucanase, oat bran, sugarcane bagasse, corn steep liquor.

\section{INTRODUCTION}

Brazil is one of the most prominent producers of lignocellulosic biomass, an abundant and renewable energy source. Apart from sugarcane bagasse and straw, other agricultural residues should be considered to prevent overdependence on a single resource (Bansal et al. 2012; Rambo et al., 2015). The utilization of lignocellulosic biomass (wheat bran, oat bran, sugarcane bagasse, sisal bagasse, etc.) as components of microbial growth media may represent cost reduction in the production of important

* Corresponding author: Rodrigo Pires do Nascimento - Dep. Engenharia Bioquímica, Escola de Química, Bloco E, sala E-108, Centro de Tecnologia, Universidade Federal do Rio de Janeiro, Ilha do Fundão, Rio de Janeiro, RJ - Brazil, 21941-909. Phone: + 5521 3938-8863.e-mail: rodrigopires@eq.ufrj.br 
enzymes, such as holocellulases and proteinases. Oat bran is one of the most common agro-industrial byproducts used as raw material in several processes and products, mainly in formulated meat products to reduce total fat and sodium, but its acceptability as a source of increased dietary fiber has been limited. It consists mainly of xylans, cellulose, starch and protein (Dawkins et al. 1999). Sugarcane bagasse is also one of the largest cellulosic agro-industrial by-products, and contains, approximately, 50\% cellulose and $25 \%$ hemicellulose and lignin (Pandey et al. 2000). In addition, corn steep liquor, a major by-product of the corn wet-milling industry, is also an inexpensive substrate available on a large scale, and has been shown to replace yeast extract very efficiently as a rich source of nutrients such as organic nitrogen and vitamins in microbial media (Akhtar et al., 1997; Nascimento et al., 2009).

Cellulose, the most common natural renewable biopolymer, is commonly degraded by the hydrolytic action of a multicomponent enzyme system (cellobiohydrolase or exoglucanases, endoglucanase or carboxymethylcellulase and cellobiase or $\beta$-glucosidase) key step for biomass conversion (Sadhu et al., 2013; Raghuwanshi et al., 2014). Endoglucanases have the ability to catalyze the hydrolysis of 1,4-b-glycosidic linkages of the amorphous regions of cellulose. In nature, endoglucanases hydrolyze cellulose in synergy with cellobiohydrolases (EC 3.2.1.91, which act upon the reducing and non-reducing ends of cellulose chains) and b-glucosidases (EC 3.2.1.21, which catalyze the hydrolysis of cellobiose into glucose). Endoglucanases have also been reported to enhance cell wall swelling and, therefore, to facilitate fibrillation when the biomass is subjected to hydrolysis before or during mechanical treatment (Teixeira et al, 2015).

In nature, several microorganisms produce endoglucanases by submerged fermentation using agro-industrial by-products as raw material (Da Vinha et al., 2011; Franco-Cirigliano et al., 2013; Sadhu et al., 2013; Teixeira et al., 2015; Oliveira et al., 2016). Microbial cellulases can be extracellular or present as aggregated structures attached to the cells, cellulosomes (Franco-Cirigliano et al., 2013; Grigorevski-Lima et al., 2013, Juturu and Wu, 2014).

Actinobacterias are a Gram positive filamentous group abundantly found in soil and the most economically important and biotechnologically valuable prokaryotes. They are responsible for the production of about half of the discovered bioactive secondary metabolites, notably enzymes (De Azeredo et al., 2006; Nascimento et al., 2009; Subramani and Aalbersberg, 2012). Streptomyces is the most important genus in the Actinobacterias group, whose species are able to produce and excrete a large variety of enzymes, such as cellulases, xylanases, proteinases (De Azeredo et al., 2006; Nascimento et al., 2009; Da Vinha et al., 2011; Franco-Cirigliano et al., 2013; Santos et al., 2015).

The microbiology of Brazilian tropical soils is largely unknown, offering excellent unexplored habitats for bioprospecting new species and enzymes belonging to this very promising group (Grigorevski-Lima et al., 2005; De Azeredo et al., 2006; Nascimento et al., 2009; Da Vinha et al., 2011; Franco-Cirigliano et al., 2013; Santos et al., 2015). Studies dealing with cellulase production by actinobacterias using low-cost residues are scarce in literature. The costs of cellulase production account for more than $40 \%$ of the total processing cost in biotechnological process (Deswal et al., 2011; Bansal et al., 2012) and our laboratory team has developed studies using low-cost raw materials as primary source. Our team has already isolated cellulolytic actinobacteria strains from Brazilian tropical soil and has obtained promising results (Nascimento et al., 2009; Da Vinha et al., 2011; Franco-Cirigliano et al., 2013). In the present paper we investigate endoglucanase production by Streptomyces diastaticus PA-01 using low-cost raw materials, such as milled sugarcane bagasse (SCB) and oat bran (OB) as carbon sources and corn steep liquor (CSL) as nitrogen source by experimental design (CCRD). The biochemical characteristics of the crude enzymatic extract were also evaluated.

\section{MATERIALS AND METHODS}

\section{Microorganism identification}

Streptomyces sp. PA-01 was isolated from a soil sample from a cave in the northeast of Brazil, using the dilution plate technique. Stock cultures were maintained on yeast extract-malt extract-agar plates (Shirling and Gottlieb, 1966) containing (g.L $\left.\mathrm{L}^{-1}\right)$ yeast extract, 4.0; malt extract, 10.0; glucose, 4.0 and agar, 15.0. Spore suspensions were prepared according to Hopwood et al. (1985) after cultivation $\left(28^{\circ} \mathrm{C} / 15\right.$ days $)$ in the same medium. Spores were maintained in $20 \%$ $(v / v)$ glycerol at $-20^{\circ} \mathrm{C}$ and Streptomyces sp. PA-01 was identified through morphological and molecular tests.

Partial sequencing of $16 \mathrm{~S}$ ribosomal RNA gene authenticated Streptomyces sp. PA-01 isolate, identified as S.diastaticus. The primers 10f (5'- GAG TTT GAT CCT GGC TCA G 3') and 1401r (5'CGG TGT GTA CAA 
GGA GGC GCC ACG 3'), homologous to the ends of the conserved $16 \mathrm{~S}$ ribosomal RNA bacteria gene were used for gene amplification. The amplified product was purified using a mini GFX column (GFX PCR DNA and Gel Band Purification Kit, GE Healthcare).

The sequencing reactions were performed with the BigDye ${ }^{\circledR}$ Terminator v3.1 Cycle Sequencing kit (Life Technologies). The primers used in the sequencing reaction were: $10 \mathrm{f}$ (5'GAG TTT GAT GGC CCT TCA G 3'), 1100r (5'AGG GGG GTG GTT GTT G 3'), 765f (5'ATT TAC AGA CCT GGT AG 3'), 782r (5'ACC AGG TCT AAT GTA CCT GT 3'), 1401r (5'CGG TGT GTA CAA GGC GCC GGA ACG 3'). Sequencing was performed in an automated sequencer $\mathrm{ABI} 3500 \mathrm{XL}$ Series (Applied Biosystems) and the sequences obtained were then processed in the program Phred / Phrap / CONSED Linux version and subjected to comparison with databases, Genbank (http://www.ncbi. nlm.nih.gov/BLAST) and Ribosomal Date Project II 9.0 (http: //dp.cme.msu .edu / index.jsp). The sequences retrieved from databases were aligned in the CLUSTAL $\mathrm{X}$ program, edited in BioEdit and phylogenetic analyses were conducted using the MEGA program version 4.

\section{Production of Endoglucanase using experimental design}

First, endoglucanase activity was qualitatively determined through Streptomyces sp. PA-01 growth on solid medium containing carboxymethylcellulose (CMC) and using Congo red to reveal CMC-degrading zones (Sazci et al., 1986).

Then, endoglucanase activity was measured after Streptomyces sp. PA-01 cultivation in $250 \mathrm{ml}$ Erlenmeyer flasks containing $50 \mathrm{ml}$ of a solution of mineral salts (Breccia et al. 1995) (in g.L $\mathrm{L}^{-1}, 2.0 \mathrm{NaCl} ; 3.0 \mathrm{KH}_{2} \mathrm{PO}_{4}$; $6.0 \quad \mathrm{~K}_{2} \mathrm{HPO}_{4} ; 0.2 \quad \mathrm{MgSO}_{4} .7 \mathrm{H}_{2} \mathrm{O} ; 0.02 \mathrm{CaCl}_{2} .2 \mathrm{H}_{2} \mathrm{O}$ ) supplemented with $1.0 \mathrm{ml}$ of trace element solution (in g. $(100 \mathrm{ml})^{-1}, 0.64 \mathrm{~g} \mathrm{CuSO}_{4} .5 \mathrm{H}_{2} \mathrm{O} ; 0.15 \mathrm{~g} \mathrm{ZnSO}_{4} .7 \mathrm{H}_{2} \mathrm{O}$; $0.11 \mathrm{~g} \mathrm{FeSO}_{4} .7 \mathrm{H}_{2} \mathrm{O} ; 0.79 \mathrm{~g} \mathrm{MnCl}_{2} \cdot 4 \mathrm{H}_{2} \mathrm{O}$ ). The initial $\mathrm{pH}$ of the medium was adjusted to 7.0. Milled sugarcane bagasse (SCB) or oat bran (OB), and corn steep liquor (CSL) were added to the culture media as the main carbon and nitrogen sources, respectively. After being milled, SCB was weighed as an irregular mixture of fiber pieces with size varying from powder to $3.0 \mathrm{~mm}$ . The culture medium was inoculated with $50 \mu \mathrm{L}$ of spore suspension $\left(1.27 \times 10^{9}\right.$ spores. $\left.\mathrm{ml}^{-1}\right)$, incubated at $30{ }^{\circ} \mathrm{C}$, and shaken $(150 \mathrm{rpm})$ for 6 days. The flasks were withdrawn every $24 \mathrm{~h}$ and their whole content centrifuged $(2,046 \times \mathrm{g} / 10 \mathrm{~min})$ and filtered through a glass filter to separate cells from the supernatant.

Optimization of the concentration of $\mathrm{OB}$ or SCB, as $\mathrm{C}$ source, and CLS as $\mathrm{N}$ source, was carried out by employing a response surface methodology (RSM) having endoglucanase activity $\left(\mathrm{U} . \mathrm{L}^{-1}\right)$ as the dependent variable and $\mathrm{C}$ source ( $\mathrm{SCB}$ or $\mathrm{OB}$ ) and $\mathrm{N}$ source (CSL) concentrations as the independent variables. A $2^{2}$ full factorial central composite rotational design (CCRD), with coded values $(-1.41,-1,0,+1,+1.41)$ was used in order to generate 11 run combinations as described in Table 1 (Deming and Morgan, 1993). This design was represented by a second-order polynomial regression model, Eq. (1), to generate contour plots:

$$
Y=b_{0}+b_{1} X_{1}+b_{2} X_{2}+b_{12} X_{1} X_{2}+b_{11} X_{1}^{2}+b_{22} X_{2}^{2}
$$

Table 1. Values of independent variables (OB or SCB concentration $\mathrm{X}_{1}$ and CSL concentration $\mathrm{X}_{2}$, respectively) used in CCRD, showing the observed values (OV) by the mathematical model for endoglucanase production by Streptomyces diastaticus PA-01.

\begin{tabular}{|c|c|c|c|c|c|c|}
\hline \multirow{2}{*}{ Run } & \multicolumn{2}{|c|}{ Coded setting levels } & \multicolumn{2}{|c|}{ Actual leves $(\% \boldsymbol{w} / \boldsymbol{v})$} & \multirow{2}{*}{$\begin{array}{c}\text { Endoglucanase } \\
\text { activity }\left(\mathrm{U}^{-1} \mathrm{~L}^{-1}\right) \mathrm{OB} \\
-4 \text { days } \\
\text { OV }\end{array}$} & \multirow{2}{*}{$\begin{array}{c}\text { Endoglucanase } \\
\text { activity }\left(\mathrm{U}^{-L^{-1}}\right) \\
\mathrm{SCB}-5 \text { days } \\
\text { OV }\end{array}$} \\
\hline & $\mathrm{X}_{1}$ & $\mathrm{X}_{2}$ & $\mathrm{X}_{1}$ & $\mathrm{X}_{2}$ & & \\
\hline 1 & -1 & -1 & 0.80 & 0.30 & 138.10 & 352.32 \\
\hline 2 & +1 & -1 & 2.40 & 0.30 & 399.75 & 393.53 \\
\hline 3 & -1 & +1 & 0.80 & 1.30 & 449.18 & 604.92 \\
\hline 4 & +1 & +1 & 2.40 & 1.30 & 485.52 & 711.98 \\
\hline 5 & -1.41 & 0 & 0.47 & 0.80 & 188.98 & 438.74 \\
\hline 6 & +1.41 & 0 & 2.73 & 0.80 & 238.04 & 701.98 \\
\hline 7 & 0 & -1.41 & 1.60 & 0.10 & 280.55 & 186.13 \\
\hline 8 & 0 & +1.41 & 1.60 & 1.51 & 617.80 & 740.53 \\
\hline 9 & 0 & 0 & 1.60 & 0.80 & 386.67 & 672.73 \\
\hline 10 & 0 & 0 & 1.60 & 0.80 & 385.22 & 678.05 \\
\hline 11 & 0 & 0 & 1.60 & 0.80 & 373.59 & 707.48 \\
\hline
\end{tabular}

Results are the mean of two experiments, $\mathrm{OV}=$ observed value 
where $Y$ is the predicted response (endoglucanase activity); $X_{1}$ and $X_{2}$ the coded forms of the input variables (OB or SCB and CSL, respectively); $b_{0}$ a constant; $b_{1}$ and $b_{2}$ the linear coefficients; $b_{12}$ a cross-product coefficient; $b_{11}$ and $b_{22}$ the quadratic coefficients. The test factors were coded according to the following regression equation:

$$
x i=\left(X_{i}-X_{0}\right) / \Delta X_{i}
$$

where $x i$ is the coded value and $X i$ the actual value of the independent variable, $X 0$ the actual value at the center point and $D X i$ is the step change value.

ANOVA (Analysis of Variance) was used to estimate the statistical parameters. The significance of the regression coefficients was determined by Student's $t$-test and the second-order model equation was determined by Fisher's test. The variance explained by the model is given by the multiple coefficient of determination, $R^{2}$. STATISTICA (version 7.0) software from StatSoft Inc. was used for regression and graphical analysis (Deming and Morgan, 1993).

The same medium used in the preliminary tests, supplemented with different combination of SCB or $\mathrm{OB}$ as carbon source and CSL as nitrogen source, was used for the experimental design (Table 1). The conditions for inoculation, incubation and filtration of supernatant for further analyses of the eleven media proposed were also the same.

\section{Enzymatic assay}

Endoglucanase activity (CMCase) was assayed by measuring the release of reducing sugars in a reaction mixture of $1.0 \mathrm{ml}$ of crude extract and $1.0 \mathrm{ml}$ of $2.0 \%$ $(w / v)$ carboxymethylcellulose (CMC) solution in $50 \mathrm{mM}$ sodium citrate buffer $(\mathrm{pH} 4.8)$ incubated at $50^{\circ} \mathrm{C}$ for $20 \mathrm{~min}$. Reducing sugars were determined by the dinitrosalicylic acid (DNS) method (Miller 1959) and detected spectrophotometrically at $540 \mathrm{~nm}$ (spectrophotometer Micronal B572). One unit (IU) of endoglucanase activity corresponded to $1 \mu \mathrm{mol}$ of glucose equivalent released per minute under the assay conditions (Ghose 1987).

\section{Crude enzyme partial characterization}

The temperature profile for endoglucanase activity (extract corresponding to the best production condition) was determined by measuring the activity at different reaction temperatures $(20,30,40,50$, $60,70,80,90$ and $100^{\circ} \mathrm{C}$ ) in $50 \mathrm{mM}$ sodium citrate buffer (pH 4.8). In the same way, the effect of $\mathrm{pH}$ on endoglucanase activity was determined using different reaction buffers $(50 \mathrm{mM}$ glycine- $\mathrm{HCl}$ for $\mathrm{pH}$ 2.0-3.0; $50 \mathrm{mM}$ sodium citrate for $\mathrm{pH} 3.0-6.0 ; 50 \mathrm{mM}$ phosphate for $\mathrm{pH}$ 6.0-8.0; $50 \mathrm{mM}$ Tris $\mathrm{HCl}$ for $\mathrm{pH} 8.0-9.0$ and 50 $\mathrm{mM}$ glycine- $\mathrm{NaOH}$ for $\mathrm{pH} 9.0-10.0$ ) at $50^{\circ} \mathrm{C}$.

For thermal stability determination the extract obtained in the best production condition was incubated at $50^{\circ} \mathrm{C}$ and the residual endoglucanase activity was measured after various time periods, $0.5,1,2,4,6$ and $8 \mathrm{~h}(18)$.

The influence of several metal ions and ethylene diamine tetracetic acid (EDTA) on endoglucanase activity was evaluated performing the enzymatic assay at $\mathrm{pH} 4.0$ and $60^{\circ} \mathrm{C}$ for $\mathrm{SCB}$ raw material and at $\mathrm{pH} 8.0$ and $50^{\circ} \mathrm{C}$ for $\mathrm{OB}$ raw material after addition of each ion (magnesium, zinc, and copper as sulfates and potassium, calcium, manganese, cobalt, sodium, iron, barium as chlorides) and EDTA at $10 \mathrm{mM}$ final concentration.

These experiments were conducted in triplicate, and the results expressed as average values.

\section{RESULTS AND DISCUSSION}

Actinobacterias are widely known for their cellulolytic potential and there are some reports in the literature about endoglucanase production (Jang and Chen, 2003; Grigorevski-Lima et al., 2005; Nascimento et al., 2009; Da Vinha et al., 2011; Franco-Cirigliano et al., 2013; Grigorevski-Lima et al., 2013). The morphological observations, characterized by long aerial mycelium, not fragmented, and the presence of diaminopimelic acid determined as LL-form suggested that the PA-01 strain could be placed in the Streptomyces genus. To confirm this, a 16S RNA sequencing analysis was carried out. The 16S rRNA gene sequences of strain PA-01 aligned to the type strain of Streptomyces diastaticus $(99.9 \% 16 \mathrm{~S}$ rRNA gene sequence identity), as shown in Figure 1.

According to the literature it is well known that actinobacterias, especially Streptomycetes, are able to degrade agro-industrial residues through lignocelluloytic enzymes, including holocellulases (Nascimento et al., 2002; Tuncer et al., 2004; Da Vinha et al., 2011; Franco-Cirigliano et al., 2013). The qualitative test (Congo red) performed for assessing Streptomyces diastaticus PA-01 cellulolytic abilities identified this strain as promising and worthy of more detailed study. The fermentation time-course for endoglucanases (CMCase) production by Streptomyces diastaticus $\mathrm{PA}-01$ in the best condition of $\mathrm{OB}$ and SCB (run 8: 1.6\% $(w / v)$ SCB or OB and 1.5\% $(w / v)$ CSL), are presented in Figure 2. S. diastaticus PA-01 strain was capable to produce the maximal enzymatic value (740.53 U.L-1) after 5-days, in the presence of $\mathrm{SCB}$. In the presence of $\mathrm{OB}$, the maximal enzymatic 


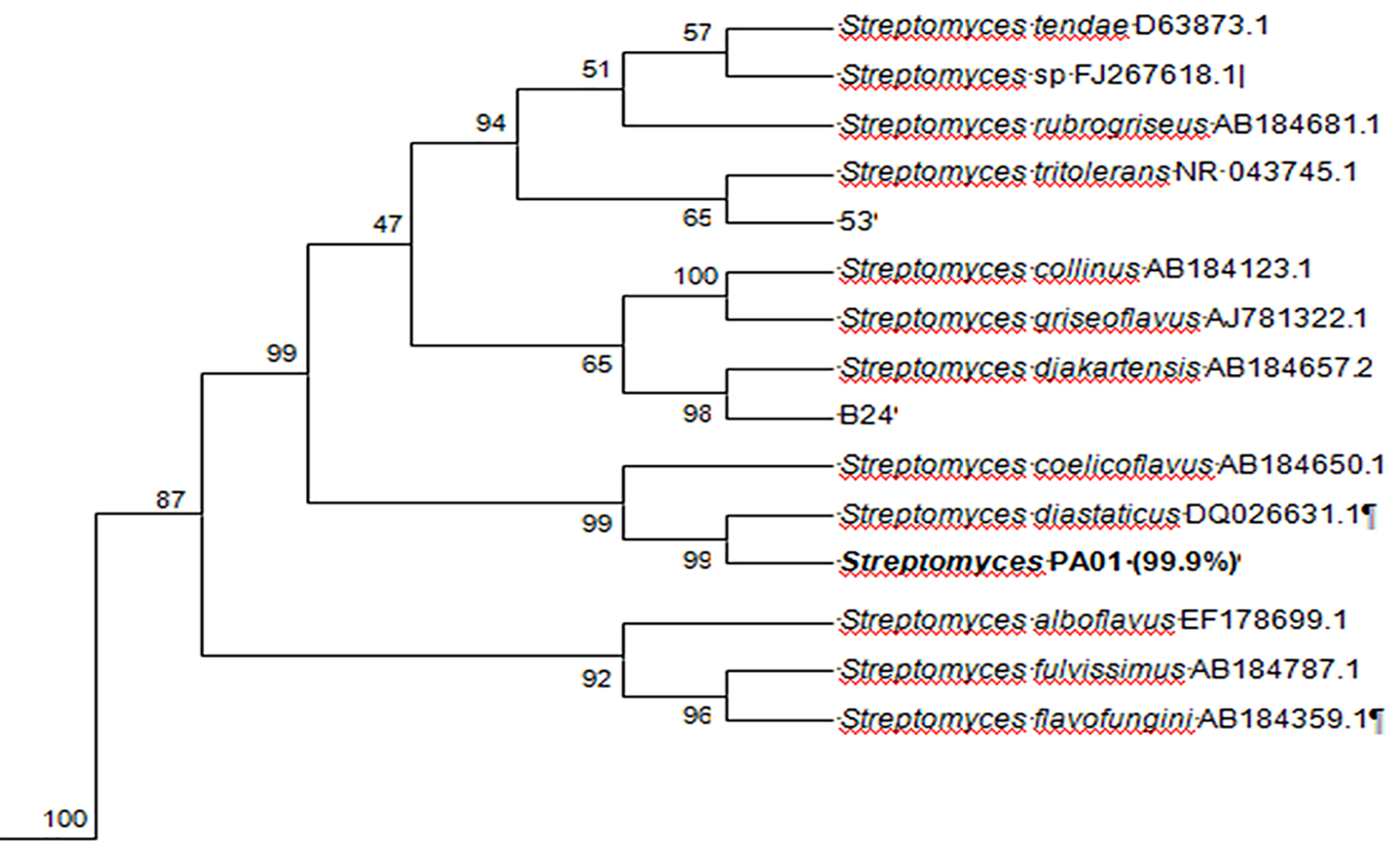

Figure 1 - Neighbour-joining phylogenetic tree created from 12 nearly complete (1,000 nucleotides) 16S rRNA gene sequences showing relationships of strain PA01 . Numbers at nodes indicate the level of bootstrap support (\%) based on a neighbour-joining analysis of 1,000 re-sampled datasets.

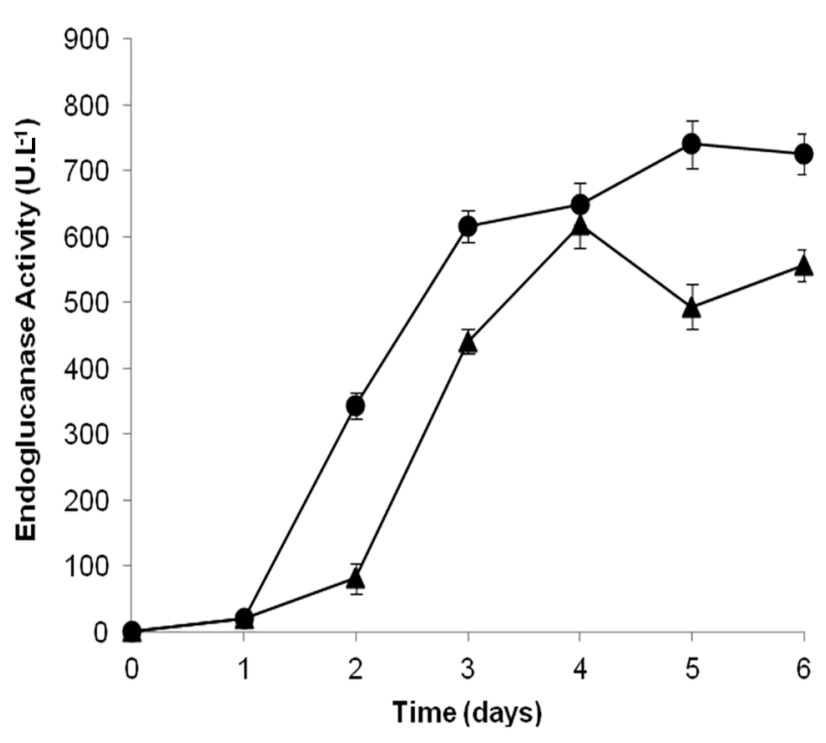

Figure 2 - Fermentation time course of endoglucanase production by Streptomyces diastaticus PA-01 on the best condition observed in $(\bullet)$ sugarcane bagasse $[1.60 \%(w / v)]+$ corn steep liquor $[1.51 \%(w / v)]$ and $(\boldsymbol{\Delta})$ oat bran $[2.40 \%(w / v)]+$ corn steep liquor $[1.30 \%(w / v)]$. Error bars represent the standard deviation of each experimental point $(n=3)$.

value (617.80 U.L $\left.\mathrm{L}^{-1}\right)$ was obtained after 4-days. After analyzing the results obtained in different fermentation times for endoglucanases production, it was possible

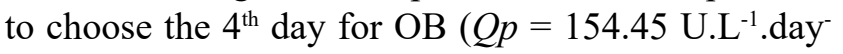
$\left.{ }^{1}\right)$ and $5^{\text {th }}$ day for $\operatorname{SCB}\left(Q p=148.11 \mathrm{U} \cdot \mathrm{L}^{-1} \cdot\right.$ day $\left.^{-1}\right)$ to perform the statistical analysis of surface response and analysis of variance (ANOVA). Table 1 presents the results obtained by Statistica 7.0 software (Statsoft ${ }^{\circledR}$ ), of CCRD matrix. Our team has been cultivating Streptomyces strains using agro-industrial residues aiming at the production of lignocellulose degradation enzymes, including endoglucanases. In the present study, similar values of endoglucanase production (700 - 1,000 U.L-1 $)$ by Streptomyces strains were detected. Nascimento et al. (2009) detected maximum endoglucanase activity $\left(719.00\right.$ U.L $\left.\mathrm{L}^{-1}\right)$ when Streptomyces malaysiensis AMT-3 strain was grown on $0.5 \%(w / v)$ brewer's spent grain (BSG) and 1.2\% $(w / v)$ CSL, after 4-days fermentation. Grigorevski-Lima et al. (2005) observed maximum endoglucanase activity (395.0 U.L ${ }^{-1}$ ) by Streptomyces drozdowiczii in the presence of $1 \%(w / v)$ wheat bran and $0.3 \%(w / v)$ yeast extract, after 2-day fermentation. Franco-Cirigliano et al. (2013) studied endoglucanase production by Streptomyces misionensis PESB-25, and the maximal production $\left(1,000\right.$ U.L $\left.\mathrm{L}^{-1}\right)$ was obtained when $1.0 \%$ $(w / v)$ SCB and $1.2 \%(w / v)$ CSL were used. Da Vinha et al. (2011) observed a high endoglucanase production by Streptomyces viridobrunneus SCPE-09, isolated from the soil of a sugarcane crop, using wheat bran (WB) and SCB as raw materials. The best condition for 
endoglucanase activity was detected when $2.0 \%(\mathrm{w} / \mathrm{v})$ WB and $0.19 \%(w / v)$ CSL $\left(2,004.0 \mathrm{U}^{-L^{-1}}\right)$ or $3.0 \%$ $(w / v)$ SCB and $1.40 \%(w / v)$ CSL $\left(1,101.0\right.$ U.L $\left.^{-1}\right)$ were used, after 5-day fermentation. Tuncer et al. (2004) studied the production of endoglucanase, among other enzymes, with Streptomyces sp. F262 grown with $1.2 \%$ ball-milled wheat straw + yeast extract. The maximum endoglucanase production $\left(1,730.0\right.$ U.L $\left.{ }^{-1}\right)$ was detected only after 7 days fermentation. However, after 5-days fermentation, no endoglucanase activity was detected for Streptomyces sp. F262. As observed, the raw materials used in these experiments were different, which could have significantly interfered in endoglucanase production by the Streptomyces strains.

There are many citations in the literature using agro-industrial by-products as raw material for endoglucanase production by microorganisms, especially sugarcane bagasse (SCB) and wheat bran (Dutta et al., 2008; Nascimento et al., 2009; Castro et al., 2010; Da Vinha et al., 2011; Franco-Cirigliano et al., 2013; Grigorevski-Lima et al., 2013; Sadhu et al., 2013; Deswal et al., 2014; Santos et al., 2015; Oliveira et al., 2016). However, comparison between these results and ours is difficult, since the conditions for endoglucanase activity and enzyme production were different. Up to the present moment, as far as we are concerned, there are not many citations in the literature using actinobacterias strains as endoglucanaseproducers, in comparison with fungal strains.

The model was tested for adequacy by the analysis of variance (ANOVA). For the SCB + CSL combination (Table 2), the computed $F$-value (36.9) indicates that the model was significant at a high confidence level. The probability $P$ value was also very low $(<0.05)$ indicating the significance of the model, since the low values of $P$ of less than 0.10 indicate the more significant correlation of coefficients. When the values of independent variables $X_{1}$ and $X_{2}$ take coded values $(-1.41,-1,0,+1,+1.41)$ the model coefficients represent the relative weight of each independent variable (carbon and nitrogen sources concentrations) towards the response (endoglucanase activity). This description is a major advantage of using statistical experimental designs. The coefficient of determination $\left(R^{2}=0.96\right)$ also indicates a very good correlation between the experimentally observed and predicted values. The mathematical model representing endoglucanase activity $(Y)$ for the combination SCB + CSL in the experimental region studied can be expressed by Eq. (3)

$$
\begin{aligned}
Y= & 686.09+65.07 X_{1}+169.38 X_{2} \\
& -58.15 X_{1}^{2}-111.66 X_{2}^{2}
\end{aligned}
$$

The coefficient of determination obtained $\left(R^{2}=\right.$ 0.96 ) indicates that $96.3 \%$ of the variability of the responses can be explained by the model used in this study with SCB + CSL.

The computed F-value (17.26) for the OB + CSL combination (Table 2) indicates the significance of the model at a high confidence level. The probability $P$ value was also very low $(<0.05)$ and the coefficient of determination $\left(R^{2}=0.95\right)$ indicated again a very good correlation between the experimentally observed and predicted values. The independent variable $\mathrm{OB}$ concentration and the interaction between OB and CSL had a significant effect $(P<0.05)$ on endoglucanase production. The mathematical model representing endoglucanase activity $(Y)$ for the combination $\mathrm{OB}+$ CSL can be expressed by Eq. (4).

$Y=381.83+45.21 X_{1}+109.22 X_{2}-75.71 X_{1}^{2}$

The coefficient of determination obtained $\left(R^{2}=\right.$ 0.95 ) indicates that $96.2 \%$ of the variability of the responses can be explained by the model used in this study with OB + CSL.

The regression analysis for the experiment using the combination SCB + CSL and OB + CSL, Eq. 3 and Eq. 4 respectively, shows the significant coefficients of the full second-order polynomial model

\begin{tabular}{|c|c|c|c|c|c|c|}
\hline & $\begin{array}{l}\text { Source of } \\
\text { variations }\end{array}$ & Sum of squares & Degrees of freedom & Mean square & $F$-value & $p$-value* \\
\hline \multirow{3}{*}{$\mathrm{SCB}+\mathrm{CSL}$} & Regression & 337784.4 & 4 & 84446.1 & \multirow{3}{*}{36.9} & \multirow{3}{*}{$<0.05$} \\
\hline & Residue & 13731.2 & 6 & 2288.5 & & \\
\hline & Total SS & 351515.6 & 10 & & & \\
\hline \multirow{3}{*}{$\mathrm{OB}+\mathrm{CSL}$} & Regression & 183286.8 & 5 & 36657.36 & \multirow[t]{3}{*}{17.26} & \multirow{3}{*}{$<0.05$} \\
\hline & Residue & 10621.6 & 5 & 2124.32 & & \\
\hline & Total SS & 193908.4 & 10 & & & \\
\hline
\end{tabular}

Table 2. Statistical analysis of variance (ANOVA) for the model of endoglucanase production at different levels of concentration of raw material used. 
of endoglucanase production, determined by Student's $t$-test and $P$-values. The resulting response surface plots showing the effect of substrate concentration (OB $+\mathrm{CSL}$ or SCB + CSL) on endoglucanase production by Streptomyces diastaticus PA-01 are presented in Figures $3 \mathrm{~A}$ and $3 \mathrm{~B}$, respectively. The authors observed a significant effect on endoglucanase production by Streptomyces diastaticus PA-01 when SCB was used as raw material.

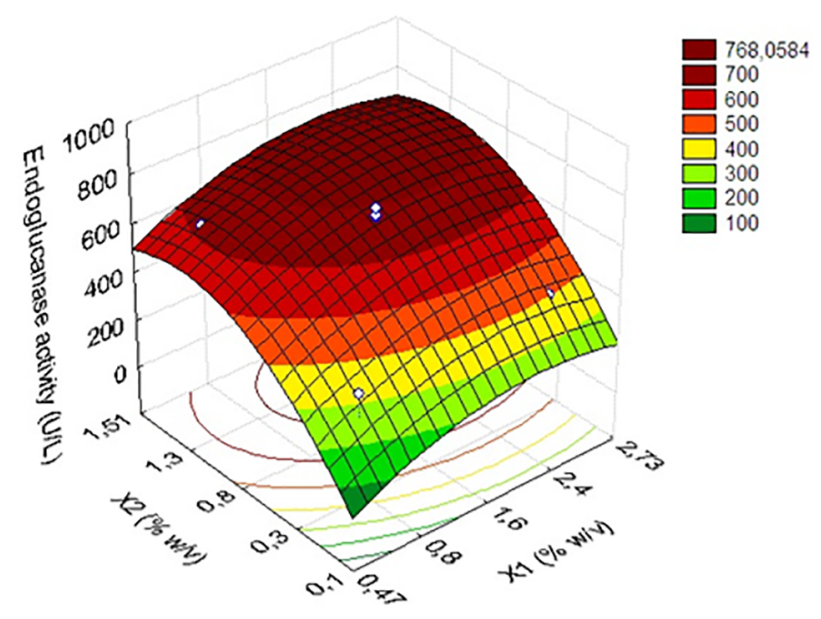

(a)

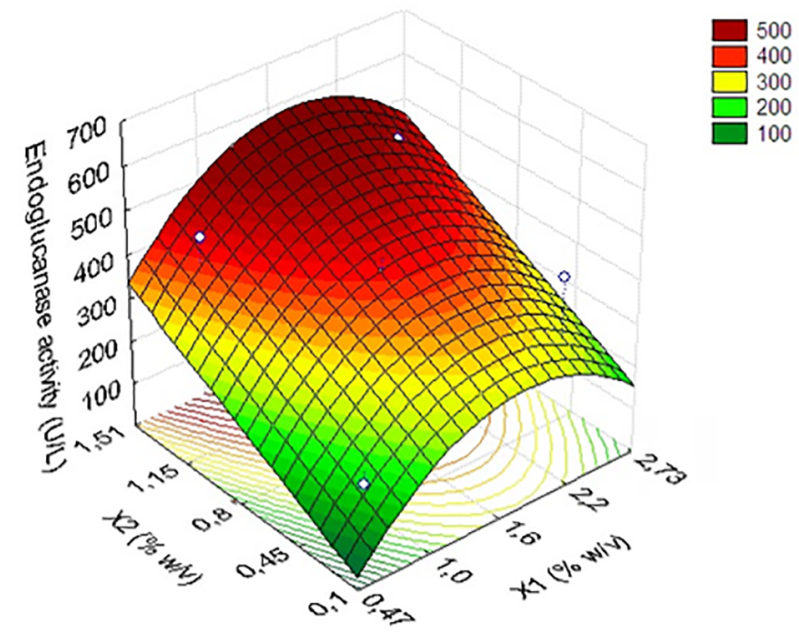

(b)

Figure 3 - Response surface for endoglucanase production by Streptomyces diastaticus PA-01 using OB and CSL (a) and SCB and CSL (b) concentration as independent variables. The full factorial central composite design $\left(2^{2}\right)$ used response surface methodology to predict the best point for Endoglucanase production.

Based on CCRD experiments and RSM trends, the validation of the mathematical model, in triplicate, showed the maximum values for endoglucanase activity obtained, 1,039.3 U.L. ${ }^{-1}$ when using $2.0 \%(w / v)$ $\mathrm{OB}+1.6 \%(w / v) \mathrm{CSL}$ and $1,180.3 \mathrm{U}^{-L^{-1}}$ when $2.4 \%$ $(w / v) \mathrm{SCB}+1.3 \%(w / v)$ CSL was used. We observed, after the experimental validation, an increase in endoglucanase activity of $59.3 \%$ and $68.2 \%$, when the concentrations of SCB + CSL and OB + CSL were modified, respectively, according to RSM indications. In these new fermentation conditions $(2.4 \%(w / v)$ $\mathrm{SCB}+1.3 \%(w / v) \mathrm{CSL})$, our team detected values of endoglucanase production similar to that of $S$. viridobrunneus SCPE- 09 in SCB (1.07-fold), higher than of $S$. malaysiensis AMT- 3 in BSG (1.64-fold) and $S$. drozdowiczii in CMC (1.98-fold) and wheat bran (2.98-fold).

The temperature profile of endoglucanase activity obtained in the crude extract from Streptomyces diastaticus PA-01 grown in SCB or OB and CSL is presented in Figure 4A. Maximum activity was observed at $50^{\circ}(\mathrm{OB})$ and $60^{\circ} \mathrm{C}(\mathrm{SCB})$. These results are similar to or even somewhat higher than those reported by some

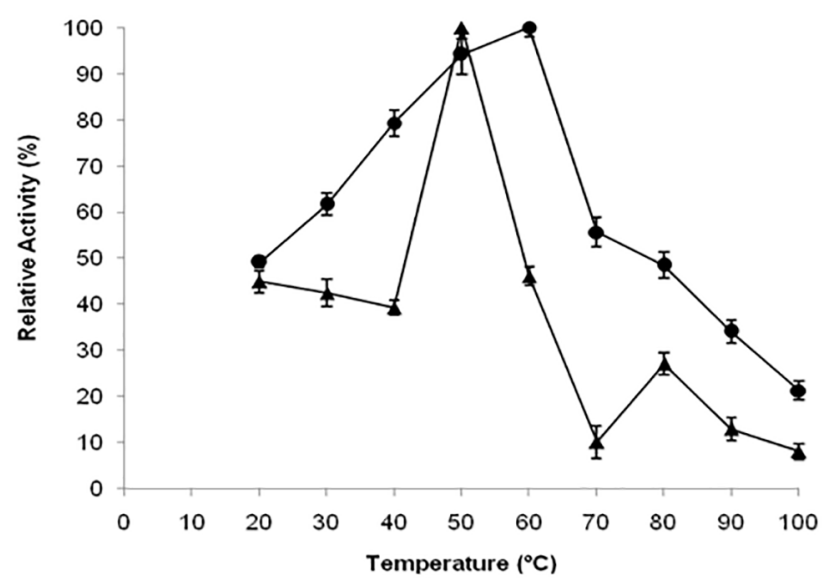

(a)

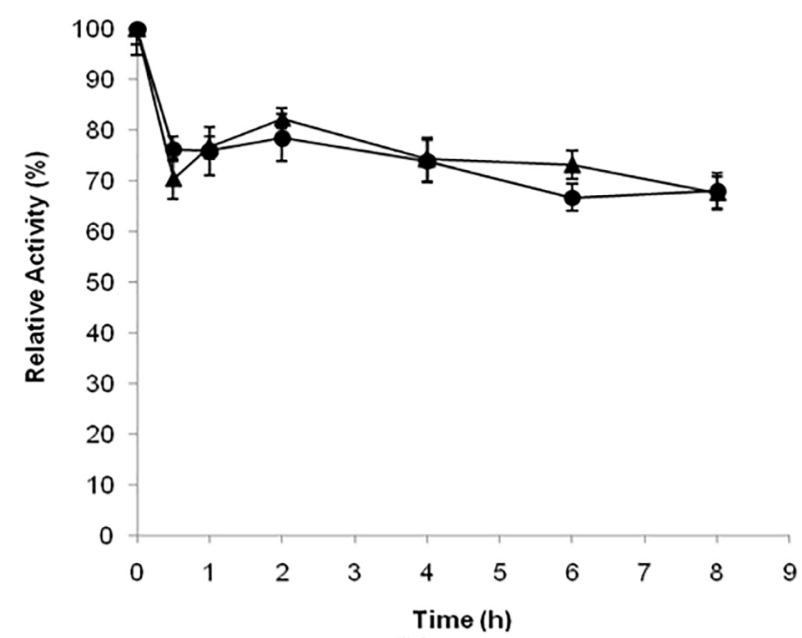

(b)

Figure 4 - Effect of temperature (a) and thermal stability (b) on activity $(\mathrm{pH} 4.8)$ of endoglucanase produced by Streptomyces diastaticus PA-01 grown on $(\mathbf{\Delta}) 2.00 \%(w / v)$ OB and $1.65 \%(w / v)$ CSL or $(\bullet) 2.40 \%(w / v)$ SCB and $1.30 \%(w / v)$ CSL. Residual activity is expressed as a percentage of the original activity. Error bars represent the standard deviation of each experimental point $(\mathrm{n}=2)$. 
authors (Grigorevski-Lima et al., 2005; Nascimento et al., 2009; Da Vinha et al., 2011; Franco-Cirigliano et al., 2013; Budihal et al., 2016) for Streptomyces strains, such as $S$. drozdowiczii $\left(50^{\circ} \mathrm{C}\right)$, S. malaysiensis AMT-3 $\left(50^{\circ} \mathrm{C}\right)$, $S$. viridobrunneus SCPE-09 $\left(50^{\circ} \mathrm{C}\right), S$. misionensis PESB-25 $\left(66^{\circ} \mathrm{C}\right)$, Streptomyces DSK59 $\left(45^{\circ} \mathrm{C}\right)$. In our studies we observed that the endoglucanase produced by Streptomyces diastaticus PA- 01 in SCB and CSL was thermophilic, showing enzymatic activity values above $80 \%$ at temperatures between $40^{\circ}$ and $60^{\circ} \mathrm{C}$ when SCB was used as substrate. The temperature profile of Streptomyces diastaticus PA-01 is a good characteristic for biotechnological application.

Thermal stability experiments are shown in Figure 4B. Crude enzyme was able to retain $73 \%$ enzymatic activity at $50^{\circ} \mathrm{C}$ for $4 \mathrm{~h}$ (SCB supernatant) and $6 \mathrm{~h}$ (OB supernatant) of pre-incubation. Da Vinha et al (2011) observed only $45 \%$ of enzymatic activity at $50^{\circ} \mathrm{C}$ after 1 hour of pre-incubation of cellulolytic supernatant (SCB as raw material) obtained using $S$. viridobrunneus SCPE-09, while Nascimento et al. (2009) observed 50\% of enzymatic activity at $50^{\circ} \mathrm{C}$ after 2 hours of pre-incubation of cellulolytic supernatant (brewer's spent grain as raw material) using S. malaysiensis AMT-3. Franco-Cirigliano et al. (2013) observed a thermal stability above $50 \%$ at $50^{\circ} \mathrm{C}$ after 4 hours of pre-incubation of cellulolytic supernatant (SCB as raw material) using $S$. misionensis PESB-25. The authors could not find the half-life of cellulolytic supernatant, because after $8 \mathrm{~h}$ of pre-incubation the enzymatic activity was approximately $70 \%$ for both raw material used (SCB and $\mathrm{OB}$ ). Our results strongly suggest that the endoglucanases produced by Streptomyces diastaticus PA-01 in these supernatants (SCB and $\mathrm{OB}$ raw material) are thermo tolerant $(>70 \%$ for 4 hours at $50^{\circ} \mathrm{C}$ ) and as such could be considered appropriate for some biotechnological processes, such as biomass hydrolysis for biorefinery purposes and industrial processes that demand long processing times at elevated temperatures, such as those in the food, sugar and fuel ethanol industries (Jang and Chen, 2003).

The $\mathrm{pH}$ profiles (Figure 5) demonstrate that $75 \%$ endoglucanase activity is maintained over a wide $\mathrm{pH}$ range (2.0 to 8.0$)$, with optimal activity occurring in three different $\mathrm{pH}$ values, according to the rawmaterial used. When OB was used as raw-material, the optimum $\mathrm{pH}$ was 4.0 (Figure 5A), while when $\mathrm{SCB}$ was used, the optimum $\mathrm{pH}$ was 3.0 (glycine- $\mathrm{HCl}$ buffer) and $\mathrm{pH} 7.0$ (Figure 5B). This is a very peculiar and interesting biochemical characteristic, not very commonly described. There are very few reports in the literature about endoglucanase activity over a very wide $\mathrm{pH}$ range (Da Vinha et al., 2011; Nascimento et al., 2009). Most reports cite activities in the alkaline range only (Dutta et al., 2008; Shanmughapriya et al., 2010). Nascimento et al. (2009) reported a pH profile within the range 2.0-9.0 (above 60\%), with maximum endoglucanase activity observed at $\mathrm{pH}$ 4.0. Da Vinha et al. (2011) observed a similar $\mathrm{pH}$ profile within the range 3.0-7.0 (above 60\%), with maximum endoglucanase activity observed at $\mathrm{pH}$ 5.0. According to George et al. (2001), endoglucanase (CMCase) from culture supernatant obtained from a species of Thermomonospora presented optimum activity at pH 5.0, whereas Jang and Chen (2003) obtained an

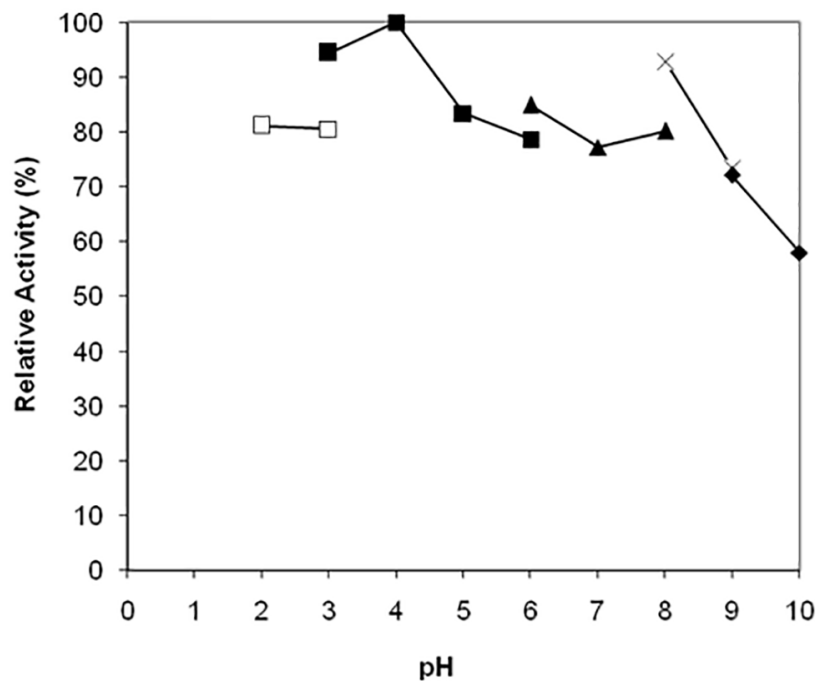

(a)

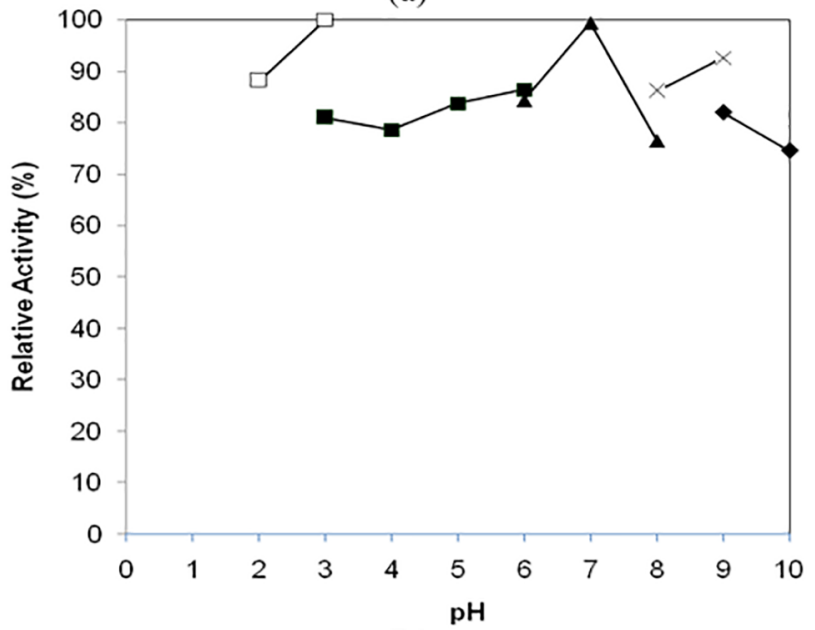

(b)

Figure 5 - Effect of $\mathrm{pH}$ on activity $\left(50{ }^{\circ} \mathrm{C}\right)$ of endoglucanase produced by Streptomyces diastaticus PA-01 grown on (a) $2.00 \%(w / v)$ OB and $1.65 \%$ $(w / v)$ CSL or (b) $2.40 \%(w / v)$ SCB and $1.30 \%(w / v)$ CSL. The ionic strength for all buffers was 50mM: (- $\square$-) glycine- $\mathrm{HCl} ;(-\boldsymbol{\square}$-) sodium citrate; (- $\boldsymbol{\Lambda}-)$ sodium phosphate; (-x-) Tris-HCl; (-४-), glycine- $\mathrm{NaOH}$. Residual activity is expressed as a percentage of the original activity. Error bars represent the standard deviation of each experimental point $(\mathrm{n}=2)$. 
endoglucanase (CMCase) produced by Streptomyces T3-1 with optimum activity at $\mathrm{pH}$ 7.0. This biochemical characteristic of the crude extract obtained in this study could represent a promising biotechnological application, especially in biofuel technologies.

Studies of the influence of metal ions are very important for industrial enzyme applications. Metal ions may be a requirement for enzymatic activity and might even be an integral component of the enzyme complex (Chinedu et al. 2008). The effect of some metal ions on the activity of endoglucanase obtained from $S$. diastaticus PA-01 is shown in Table 3. Two distinct situations are noteworthy concerning the carbon source used for enzyme production. When SCB was used as carbon source, all ions and EDTA tested, at $10.0 \mathrm{mM}$, inhibited endoglucanase activity, especially $\mathrm{Cu}^{2+}$ and $\mathrm{Ca}^{2+}$, which showed a strong inhibition (above $96 \%$ ). A reasonable decrease in endoglucanase residual activity was observed only in the presence of $\mathrm{Mn}^{2+}$ and $\mathrm{Zn}^{2+}$, showing 40\% inhibition (Table 3). This antagonistic effect was not observed by Franco-Cirigliano et al. (2013) using the same carbon source (SCB), at a concentration of $2 \mathrm{mM}$. Those authors observed that, when $\mathrm{Mn}^{2+}$ and $\mathrm{Co}^{2+}$ were added in the $S$. misionensis PESB-25 supernatant, there was a significant increase in endoglucanase activity $(101.5 \%$ and $61.2 \%$, respectively). In contrast, the other ions tested $\left(\mathrm{Zn}^{2+}\right.$, $\left.\mathrm{Ba}^{2+}, \mathrm{Fe}^{2+}, \mathrm{K}^{+}, \mathrm{Na}^{+}, \mathrm{Ca}^{2+}, \mathrm{Mg}^{2+}\right)$ and EDTA, increased the residual endoglucanase activity between $9.3 \%$ and $40.6 \%$, less than observed for $\mathrm{Co}^{2+}$ and $\mathrm{Mn}^{2+}$ (FrancoCirigliano et al., 2013). Grigorevski-Lima et al. (2005) detected 30\% inhibition in the presence of $\mathrm{Cu}^{2+}$ in the enzymatic supernatant from $S$. drozdowiczii grown in low viscosity carboxymethylcellulose. However, endoglucanases residual activity was induced in the presence of $\mathrm{Ba}^{2+}(+85.9 \%), \mathrm{Fe}^{2+}(+35.3 \%), \mathrm{K}^{+}(+$ $62.4 \%), \mathrm{Na}^{+}(+9.4 \%), \mathrm{Mg}^{2+}(+23.5 \%)$. Endoglucanases activity is probably inhibited through the attack of some groups to the active site of the enzyme, for example, the thiol groups, leading to inactivation.

On the other hand, when OB was used as carbon source for endoglucanase production, only $\mathrm{Cu}^{2+}$ had a negative effect on residual endoglucanase activity, showing an inhibition of about $35 \%$. This results are very interesting, because the ions $\mathrm{Zn}^{2+}, \mathrm{Ba}^{2+}, \mathrm{Fe}^{2+}$, $\mathrm{K}^{+}, \mathrm{Na}^{+}, \mathrm{Co}^{2+}, \mathrm{Ca}^{2+}, \mathrm{Mg}^{2+}, \mathrm{Mn}^{2+}$ are commonly cited in the literature as inhibitors for several microbial cellulases (Dutta et al., 2008; Nascimento et al., 2009; Shanmughapriya et al., 2010; Da Vinha et al., 2011). In the present experiments, the addition of $\mathrm{Mn}^{2+}$ and $\mathrm{Zn}^{2+}$ to the $S$. diastaticus PA-01 supernatant resulted in significant increases in endoglucanase activity (111.58\% and $85.4 \%$, respectively). According to Chauvaux et al. (1995) $\mathrm{Mn}^{2+}$ and other metal ionscan enhance the substrate binding affinity of the enzyme and stabilize the conformation of the catalytic site. The addition of $\mathrm{Fe}^{2+}$ resulted in about a $41 \%$ increase in residual endoglucanases activity, similar to results reported by Grigorevski-Lima et al (2005), who showed that endoglucanase activity of $S$. drozdowiczii M7A increased $35.3 \%$ in the presence of $\mathrm{Fe}^{2+}$. Santos et al. (2012) also reported a positive effect after the addition of $\mathrm{Mn}^{2+}$ to Bacillus subtilis cellulase 5A supernatant. The positive effect on residual endoglucanases activity $(+30 \%)$, after the addition of $\mathrm{Mn}^{2+}(4.0 \mathrm{mM})$, was also observed in supernatant obtained from Aspergillus

Table 3. Effect of different ions on endoglucanase activity. Enzyme was produced by Streptomyces diastaticus PA- 01 grown on $2.00 \%$ ( $w / v$ ) OB and $1.65 \%$ $(w / v)$ CSL or $2.40 \%(w / v)$ SCB and $1.30 \%(w / v)$ CSL.

\begin{tabular}{lcc}
\hline Ion $^{\mathrm{a}}$ & $\begin{array}{c}\text { SCB }+ \text { CSL } \\
\text { Relative activity (\%) } \mathbf{~}^{\mathbf{b}}\end{array}$ & $\begin{array}{c}\text { OB + CSL } \\
\text { Relative activity (\%) }{ }^{\mathbf{b}}\end{array}$ \\
\hline Control (no addition) & 100.00 & 100.00 \\
$\mathrm{Zn}^{+2}$ & 62.96 & 185.39 \\
$\mathrm{Ba}^{+2}$ & 44.98 & 179.61 \\
$\mathrm{Fe}^{+2}$ & 29.51 & 141.17 \\
$\mathrm{~K}^{+}$ & 33.87 & 172.12 \\
$\mathrm{Mn}^{+2}$ & 61.17 & 211.58 \\
$\mathrm{Co}^{+2}$ & 37.22 & 174.85 \\
$\mathrm{Na}^{+}$ & 30.53 & 152.39 \\
$\mathrm{Ca}^{+2}$ & 3.35 & 166.00 \\
$\mathrm{Cu}^{+2}$ & 1.79 & 64.97 \\
$\mathrm{Mg}^{+2}$ & 24.97 & 162.94 \\
$\mathrm{EDTA}$ & 29.33 & 143.55 \\
\hline
\end{tabular}

${ }^{a}$ The final concentration in the reaction mixture was $10 \mathrm{mM}$.

belative activity is expressed as a percentage of control

$\left(\mathrm{SCB}-100 \%\right.$ of enzyme activity $=1,674.0 \mathrm{U} \cdot \mathrm{L}^{-1}$ and $\mathrm{OB}-100 \%$ of enzyme activity $\left.=1,237.0 \mathrm{U} \cdot \mathrm{L}^{-1}\right)$. 
glaucus when SCB was used as raw-material (Yi-Ming et al., 2010). In our results, the increase of residual endoglucanase activity, obtained when $\mathrm{OB}$ was used as raw material, was above $50 \%$ for the ions $\mathrm{Mn}^{2+}, \mathrm{Co}^{2+}, \mathrm{K}^{+}$, $\mathrm{Zn}^{2+}, \mathrm{Ba}^{2+}, \mathrm{Na}^{+}, \mathrm{Ca}^{2+}, \mathrm{Mg}^{2+}$ (Table 3). The use of EDTA also increased the residual endoglucanase activity by $43.6 \%$. According to these results these ions must be avoided in future cultivations for a good endoglucanase production and as supplement in enzymatic crude extracts to increase the endoglucanase activity.

\section{CONCLUSION}

The microorganism Streptomyces diastaticus PA01 used in this study was able to grow and to produce endoglucanase using oat bran(OB) or sugarcane bagasse (SCB) and corn steep liquor (CSL) as sources of $\mathrm{C}$ and $\mathrm{N}$, respectively. The maximum endoglucanase activity detected was 1,180.3 U.L L $^{-1}$, after 5-day fermentation, when a mineral medium was supplemented with $2.40 \%$ $(w / v)$ SCB and $1.30 \%(w / v)$ CSL. These results were obtained after experimental validation of CCRD used for enzyme production optimization. The experimental design resulted in a 1.68 and 1.59-fold improvement on endoglucanase production (for $\mathrm{OB}$ and $\mathrm{SCB}$, respectively) when compared to the initial factorial planning. The optimum conditions of the crude extract obtained from SCB + CSL were $\mathrm{pH}$ of 3.0 and 7.0 and temperature of $60^{\circ} \mathrm{C}$, and the endoglucanase retained $73 \%$ activity after 4 hours at $50^{\circ} \mathrm{C}$. The extract obtained from OB + CSL showed the optimum conditions in $\mathrm{pH} 4.0$ and temperature of $50^{\circ} \mathrm{C}$. The activity of these endoglucanases was strongly enhanced in the presence of a number of metal ions, when $\mathrm{OB}$ was used as carbon source for enzyme production. $10 \mathrm{mM} \mathrm{Mn}^{2+}$ increased residual endoglucanase activity $\left(2,617.24\right.$ U.L L $\left.^{-1}\right)$ by $111 \%$. This level of activity is one of the highest described in literature for endoglucanase production by Streptomyces strains using low-cost residues as substrates. Considering the low cost of the medium, and the high titers obtained for enzymatic activity, the results obtained in the present study indicate a possible use for these enzymes in biotechnology processes, especially for bioethanol production.

\section{ACKNOWLEDGEMENTS}

This study was supported by Fundação de Amparo a Pesquisa do Estado da Bahia (FAPESB), Conselho Nacional de Desenvolvimento Científico e Tecnológico (MCT/CNPq) and Coordenação de Aperfeiçoamento de Pessoal do Ensino Superior (CAPES).

\section{REFERENCES}

Akhtar, M., Lentz, M.J., Blanchette, R.A., Kirk, T.K., Corn steep liquor lowers the amount of inoculums for biopulping. TAPPI Journal, 80(6) 161-164 (1997).

Bansal, N., Tewari, R., Soni, R., Soni, S.K., Production of cellulases from Aspergillus niger NS- 2 in solid state fermentation on agricultural and kitchen waste residues. Waste Management, 32 1341-1346 (2012). DOI: 10.1016/j.wasman.2012.03.006

Breccia, J.D., Castro, G.R., Baigori, M.D., Sineriz, F., Screening of xylanolytic bacteria using a colour plate method. J. Appl. Bacteriol., 78(5) 469-472 (1995). DOI: 10.1111/j.1365-2672.1995.tb03086.x

Budihal, S.R., Agsar, D., Patil, S.R.,) Enhanced production and application of acidothermophilic Streptomyces cellulase. Biores. Technol., 200, 706712 (2016. DOI:10.1016/j.biortech.2015.10.098

Castro, A.M., Carvalho, M.L.A., Leite, S.G.F., Pereira Jr., N., Cellulases from Penicillium funiculosum: production, properties and application to cellulose hydrolysis. J. Ind. Microbiol. Biotechnol., 37 151158 (2010). DOI: 10.1007/s10295-009-0656-2

Chauvaux, S., Souchon, H., Alzari, P.M., Chariot, P., Beguin, P., Structural and functional analysis of the metal-binding sites of Clostridium thermocellum endoglucanase CelD. J. Biol. Chem., $2709757-$ 9762 (1995). DOI: 10.1074/jbc. 270.17.9757

Chinedu, S.N., Nwinyi, C.O., Okochi, V.I., Properties of endoglucanase of Penicillium chrysogemum PCL501. Australian J. Basic Appl. Sci., 2 738-746 (2008).

Da Vinha, F.N.M., Gravina-Oliveira, M.P., Franco, M.N., Macrae, A., Bon, E.P.S., Nascimento, R.P., Coelho, R.R.R., Cellulase Production by Streptomyces viridobrunneus SCPE-09 Using Lignocellulosic Biomass as Inducer Substrate. Appl. Biochem. Biotechnol., 164 256-267 (2011). DOI: $10.1007 / \mathrm{s} 12010-010-9132-8$

Dawkins, N.L., Phelps, O., McMillin, K.W., Forrester, I.T., Composition and physicochemical properties of chevon patties containing oat bran. J. Food Sci., 64(4) 597-600 (1999). DOI: 10.1111/j.13652621.1999.tb15092.x

De Azeredo, L.A.I., De Lima, M.B., Coelho, R.R.R., Freire, D.M.G., A low-cost fermentation medium for thermophilic protease production by Streptomyces sp. 594 using feather meal and corn steep liquor. Curr, Microbiol., 53 335-339 (2006). DOI: $10.1007 / \mathrm{s} 00284-006-0163-\mathrm{x}$ 
Deming, S.N., Morgan, S.L., Experimental Design: a Chemometric Approach, 2 ${ }^{\text {nd }}$ edition. Elsevier Science Publishers BV, Amsterdam (1993). ISBN: 9780444548269

Deswal, D., Khasa, Y.P., Kuhad, R.C., Optimization of cellulase production by a brown rot fungus Fomitopsis sp. RCK2010 under solid state fermentation. Biores. Technol., 102 6065-6072 (2011). DOI: 10.1016/j.biortech.2011.03.032

Dutta, T., Sahoo, R., Sengupta, R., Ray, S.S., Bhattacharjee, A., Ghosh, S., Novel cellulases from an extremophilic filamentous fungi Penicillium citrinum: production and characterization. J. Ind. Microbiol. Biotechnol., 35 275-282 (2008). DOI: 10.1007/s10295-008-0304-2

Franco-Cirigliano, M.N., Rezende, R.C., GravinaOliveira, M.P., Pereira, P.H.F., Nascimento, R.P., Bon, E.P.S., Macrae, A., Coelho, R.R.R., Streptomyces misionensis PESB-25 produces a thermoacidophilic endoglucanase using sugarcane bagasse and corn steep liquor as the sole organic substrates. Biomed. Res. Int., 2013 1-9 (2013). Article ID 584207. DOI: 10.1155/2013/584207

George, S.P., Ahmad, A., Rao, M.B., Studies on carboxymethyl cellulase produced by an alkalothermophilic actinobacteria. Biores. Technol., 77 171-175 (2001).

Ghose, T.K., Measurement of cellulase activities. Pure Appl. Chem., 59 257-268 (1987).

Grigorevski-Lima, A.L., Nascimento, R.P., Bon, E.P.S., Coelho, R.R.R., Streptomyces drozdowiczii cellulase production using agrondustrial byproducts and its potential use in the detergent and textile industries. Enz. Microb. Technol., 37 272277 (2005). DOI:10.1016/j.enzmictec.2005.03.016 Grigorevski-Lima, A.L., Oliveira, M.M.Q., Nascimento, R.P., Bon, E.P.S., Coelho, R.R.R., Production and Partial characterization of cellulases and xylanases from Trichoderma atroviride 676 using lignocellulosic residual biomass. Appl. Biochem. Biotechnol., 169 1373-1385 (2013). DOI: $10.1007 / \mathrm{s} 12010-012-0053-6$

Hopwood, D.A., Bibb, M.J., Chater, K.F., Kieser, T., Bruton, C.J., Kieser, H.M., Lydiate, D.J., Smith, C.P., Ward, J.M., Schrempf, H., Genetic manipulation of Streptomyces. A laboratory Manual. The John Innes Institute, Norwich, UK (1985).

Jang, H.D., Chen, K.S., Production and characterization of thermostable cellulases from Streptomyces transformant T3-1. World J. Microbiol. Biotechnol., 19 263-268 (2003). DOI: 10.1023/A:1023641806194
Juturu, V., Wu, J.C., Microbial cellulases: Engineering, production and applications. Renew. Sustain. Energ. Rev., 33 188-203 (2014). DOI:10.1016/j. rser.2014.01.077

Miller, L., Use of dinitrosalicylic acid reagent for determination of reducing sugar. Anal. Chem., 31 426-428 (1959).

Nascimento, R.P., Alves Jr, N., Pereira Jr, N., Bon, E.P.S., Coelho, R.R.R., Brewer's spent grain and corn steep liquor as substrates for cellulolytic enzymes production by Streptomyces malaysiensis. Lett. Appl. Microbiol., 48 529-535 (2009). DOI: 10.1111/j.1472-765X.2009.02575.x

Oliveira, M.M.Q., Grigorevski-Lima, A.L., Bon, E.P.S., Coelho, R.R.R., Nascimento, R.P., Production of thermophilic and acidophilic endoglucanases by mutant Trichoderma atroviride $102 \mathrm{C} 1$ using agro-industrial by-products. African J. Biotecnol., 15(11) 423-430 (2016).

Pandey, A., Soccol, C.R., Nigam, P., Soccol, V.T., Biotechnological potential of agro-industrial residues. I: sugar cane bagasse. A review. Biores. Technol., 74 69-80 (2000). DOI: 10.1016/S0960-8524(99)00142-X

Raghuwanshi, S., Deswal, D., Karp, M., Kuhad, R.C., Bioprocessing of enhanced cellulose production from a mutant of Trichoderma asperellum RCK2011 and its application in hydrolysis of cellulose. Fuel, 124 183-189 (2014). DOI:10.1016/j.fuel.2014.01.107

Rambo, M.K.D., Schmidt, F.L., Ferreira, M.M.C., Analysis of the lignocellulosic components of biomass residues for biorefinery opportunities. Talanta, 144 696-703 (2015). DOI: 10.1016/j.talanta.2015.06.045.

Sadhu, S., Saha, P., Sen, S.K., Mayilraj, S., Maiti, T.K., Production, purification and characterization of a novel thermotolerant endoglucanase (CMCase) from Bacillus strain isolated from cow dung. SpringerPlus, 2(1), 10 (2013).. DOI:10.1186/21931801-2-10

Santos, C.R., Paiva, J.H., Sforça, M.L., Neves, J.L., Navarro, R.Z., Cota, J., Akao, P.K., Hoffmam, Z.B., Meza,A.N., Smetana, J.H., Nogueira, M.L., Polikarpov, I., Xavier-Neto, J., Squina, F.M., Ward, R.J., Ruller, R., Zeri, A.C., Murakami, M.T., Dissecting structurefunction-stability relationships of a thermostable GH5CBM3 cellulase from Bacillus subtilis 168. Biochem. J., 441(1) 95-104 (2012). DOI: 10.1042/BJ20110869.

Santos, D.B., Bispo,, A.S.R., Nascimento, R.P., Cazetta, M.L., Bagaço de cana-de-açúcar e bagaço de sisal como substratos indutores para a produção de endoglucanase por actinobacteria isolada de solo de cultura de sisal. Magistra, 27(2) 245-254 (2015). 
Sazci,A., Radford,A., Erenler, K., Detection of cellulolytic fungi by using Congo red as an indicator: a comparative study with the dinitrosalicylic acid reagent method. J. Appl. Bacteriol., 61 559-562 (1986).

Shanmughapriya, S., Kiran, G.S., Selvin, J., Thomas, T.A., Rani, C., Optimization, purification and characterization of extracellular mesophilic alkalophiline cellulose from sponge-associated Marinobacter sp. MSI032. Appl. Biochem. Biotechnol., 162 625-640 (2010). DOI: 10.1007/ s12010-009-8747-0

Shirling, E.B., Gottlieb, D., Methods for characterization of Streptomyces species. Int. J. Syst. Bacteriol., 16(3) 313-340 (1966).

Subramani, R.,Aalbersberg, W., Marine actinomycetes: an ongoing source of novel bioactive metabolites. Microbiol. Res., 167(10) 571-580 (2012). DOI:10.1016/j.micres.2012.06.005.
Teixeira, R.S.A., Silva, A.S., Jang, J.H., Kim, H.W., Ishikawa,K.,Endo,T.,Lee,S.H.,Bon,E.P.S.,Combining biomass wet disk milling and endoglucanase/bglucosidase hydrolysis for the production of cellulose nanocrystals. Carbohyd. Pol., 128 75-81 (2015). DOI: 10.1016/j.carbpol.2015.03.087

Tuncer, M., Kuru, A., Isikli, M., Sahin, N., Çelenk, F.G., Optimization of extracellular endoxylanase, endoglucanase and peroxidase production by Streptomyces sp. F2621 isolated in Turkey. J. Appl. Microbiol., 97 783-791 (2004).

Tao, Y. M., Zhu, X. Z., Huang, J. Z., Ma, S. J., Wu, X. B., Long, M. N., Chen, Q. X., Purification and properties of endoglucanase from a sugar cane bagasse hydrolyzing strain, Aspergillus glaucus XC9. Journal of Agricultural and Food Chemistry, 58(10) 6126-6130 (2010). DOI: 10.1021/ jf1003896. 